\title{
Contrasting soil fungal communities at different habitats in a revegetated copper mine wasteland
}

\author{
Jie-liang Liang ${ }^{1,}$, Jun Liu ${ }^{2,}$, Tao-tao Yang ${ }^{2}$, Pan-deng Wang ${ }^{2}$, Sheng-chang Zhang ${ }^{2}$, Pu Jia ${ }^{1}$, Bin Liao ${ }^{2}$, \\ Wen-sheng Shu', Jin-tian $\mathrm{Li}^{1,2, *}$ \\ 1 Institute of Ecological Science and Guangdong Provincial Key Laboratory of Biotechnology for Plant Development, School of Life Sciences, \\ South China Normal University, Guangzhou 510631, China \\ 2 School of Life Sciences, Sun Yat-sen University, Guangzhou 510275, China
}

\section{ARTICLE INFO}

Article history:

Received January 7, 2020

Accepted January 8, 2020

Keywords:

Extremely acidic

Fungal community structure

Mine soil

Next generation sequencing

Phytostabilization

Restoration

\begin{abstract}
A B S TR A C T
Little is known about the responses of soil fungal communities to revegetation of mine wastelands, representing a major gap in the knowledge needed to improve the performances of revegetation schemes for mine wastelands. To shed some light on this matter, we reestablished $4000 \mathrm{~m}^{2}$ of vegetation on an extremely acidic $(\mathrm{pH} 2.5)$ copper mine tailings pond and collected soil samples from three different types of habitats: amended layer of the reclaimed tailings (ALRT), unamended layer of the reclaimed tailings (ULRT), and unreclaimed tailings (UT). Soil fungal communities in the 120 samples collected in two consecutive years were characterized via high-throughput sequencing. The fungal diversities at ALRT and ULRT were found to be significantly higher than those at UT. Ascomycota whose relative abundance ranged from $74.5 \%$ to $98.4 \%$ was the most predominant phylum across all habitats, exhibiting the lowest predominance at ALRT. Two acidophilic fungal genera, Acidomyces and Acidiella, dominated UT with relative abundances being as high as $37.8 \%$ and $15.2 \%$, respectively. In contrast, three genera with plant growth-promoting species (Talaromyces, Trichoderma and Penicillium) were abundant at ULRT and ALRT. Remarkably, their relative abundances at ULRT could be up to $29.0 \%, 26.9 \%$ and $9.7 \%$, respectively. The three types of habitats differed considerably in the overall soil fungal community composition at species level, which became more pronounced as time progressed. The abovementioned differences between habitats in soil fungal community features were related to the reduced availability of soil copper and zinc. These results improved our understanding of fungal ecology of mine wastelands.
\end{abstract}

(c) Higher Education Press 2020

\section{Introduction}

Mine tailings are a major category of large-volume wastes generated from mining and mineral exploitation processes

\footnotetext{
* Corresponding author

E-mail address: lijintian@m.scnu.edu.cn (J.T. Li)

'These authors have contributed equally to this work.
}

(Dudka and Adriano, 1997). For example, it has been reported that approximately $12900 \mathrm{Mt}$ of copper (Cu) mine tailings were generated in the USA during the 20th century (Gordon, 2002), while the figure for China during 1949-2007 was estimated to be roughly $2400 \mathrm{Mt}$ (Yu et al., 2009). Moreover, mine tailings can contain high levels of toxic metals, such as cadmium (Cd), copper $(\mathrm{Cu})$, lead $(\mathrm{Pb})$, and zinc ( $\mathrm{Zn}$ ) (Dudka and Adriano, 1997). Despite this, they are often disposed of by simply deposition into tailings ponds and lagoons (Dudka and Adriano, 1997). After abandonment, these de-watered tailings 
ponds, as a major type of mine wastelands, pose serious environmental and health threats through wind and water erosion (Dudka and Adriano, 1997; Mendez and Maier, 2008). The environmental problems associated with abandoned mine tailings areas are of world-wide concern (Mendez and Maier, 2008).

Revegetation aims to establish a stable vegetative cover on mine tailings ponds (or other types of mine wastelands) and thereby to reduce the wind-blow of contaminated particulates and water pollution associated with abandoned mine tailings ponds (Tordoff et al., 2000; Mendez and Maier, 2008). This approach has at least two major advantages over traditional physico-chemical treatment techniques for mine tailings ponds. First, revegetation is an in situ plant-based technology for site restoration. That is, the re-established ecosystems take advantage of the energy from plant photosynthesis, and may become self-sustainable and visually attractive after a period of establishment (Tordoff et al., 2000). Secondly, revegetation is relatively cost-effective. It has been estimated that revegetation can be as much as 17 times cheaper than physico-chemical treatment techniques (Mendez and Maier, 2008). Owing to its advantages, this type of revegetation has attracted much attention and often proven successful at specific sites (see Li and Huang, 2015 for a recent review), although the time that it takes to function is always longer than those of traditional physico-chemical treatment techniques (Tordoff et al., 2000; Mendez and Maier, 2008). Nonetheless, the widespread application of revegetation remains limited by its inconsistent performances over a range of mine tailings ponds with different geochemical properties (Tordoff et al., 2000; Mendez and Maier, 2008; Li and Huang, 2015). In particular, there have been too few reports on revegetation of extremely acidic $(\mathrm{pH}<3$ ) mine tailings (see Yang et al., 2016 and the references therein), although acidification occurs widely in sulphidic mine tailings (Johnson, 2003). A major difficulty in practicing revegetation on highly acidic mine wastelands lies in the selection of suitable plant species (e.g., metal- and acid-tolerant fast-growing herb legumes) and the maintenance of their growth during revegetation, especially given that such wastelands are deficient in soil nutrients (Tordoff et al., 2000; Mendez and Maier, 2008; Li and Huang, 2015). The addition of soil amendments, such as lime, manures and sewage sludges, is a widely used method to improve plant growth conditions. After colonizing mine wastelands, plants can function to immobilize heavy metals via adsorption onto roots, accumulation by roots and precipitation within their rhizospheres. Such processes always result to reduced metal mobility and also bioavailability (Tordoff et al., 2000; Mendez and Maier, 2008; Li and Huang, 2015).

Soil fungi are known as integral ecosystem agents that drive many below-ground nutrient cycling processes and thereby regulate the development of soil-vegetation system (van der Heijden et al., 2008). As mentioned above, revegetation of mine tailings ponds generally requires the addition of organic amendments (e.g. manures and/or sewage sludges) to mine tailings to facilitate plant growth (Tordoff et al., 2000; Mendez and Maier, 2008), which is expected to have profound effects on soil fungal communities. Such effects will in turn affect the maintenance and functions of re-established ecosystems on mine tailings (Mendez and Maier, 2008). It is therefore of paramount importance to get a clear understanding of how soil fungal communities respond to revegetation of mine tailings. However, as yet, these responses have been poorly studied. In fact, there have been only seven prior studies that have explored these responses on metalliferous mine soils (Renella et al., 2008; Ascher et al., 2009; Solís-Domínguez et al., 2011; Dos Santos et al., 2013; Valentín-Vargas et al., 2014; Zornoza et al., 2015; Kohler et al., 2016). Among them, three were based on field experiments (Dos Santos et al., 2013; Zornoza et al., 2015; Kohler et al., 2016) and four on laboratory experiments (Renella et al., 2008; Ascher et al., 2009; Solís-Domínguez et al., 2011; Valentín-Vargas et al., 2014). While either a culture-dependent approach or a phospholipid fatty acid (PLFA) analysis was employed in the field-based studies to characterize the soil fungal community, denaturing gradient gel electrophoresis (DGGE) analysis has commonly been used in laboratory-based studies. The apparent limitations of the microbiological methods used in these previous studies include (Kirk et al., 2004; Marschner, 2007; Rastogi and Sani, 2011): (i) current standard laboratory methods are considered to be unable to culture $99 \%$ of soil fungi; (ii) the number of signature fatty acids for soil fungi are limited and little community composition information can be inferred from fatty acids and (iii) DGGE generally detects only abundant taxonomies of soil fungi. Due to these reasons, our knowledge regarding the responses of soil fungal communities to revegetation of mine soils remains limited. Indeed, we do not even have information on the dominant fungal phyla and/ or genera in mine tailings (Thavamani et al., 2017), let alone their responses to revegetation.

During the last decade, next-generation sequencing technologies have revolutionized our ability to characterize soil fungal communities by making it possible to recover massive amounts of DNA sequence data directly from environmental samples at a reasonable cost (Shokralla et al., 2012). Moreover, the development of metagenomics has suggested the possibility that we may get a better understanding of changes in microbial metabolic potential following revegetation of mine wastelands through analyzing metagenomes from related experiments. To date, however, there are only two metagenomic studies on the topic (Gastauer et al., 2019; Sun and Badgley, 2019). By comparing 15 soil metagenomes from a post-mining forest rehabilitation chronosequence spanning 6-31 years plus an unmined reference forest, Sun and Badgley (2019) showed significant differences between these metagenomes in the relative abundances of genes involved in carbon $(\mathrm{C})$ cycling but not in those of genes responsible for nitrogen $(\mathrm{N})$ cycling. In contrast, the paper of Gastauer et al. (2019) only provided a complete data set of 34 soil metagenomes from a post-mining rehabilitation chron- 
osequence spanning 0-6 years plus three reference sites, but did not make any detailed analysis of or discussion on the data set. Nonetheless, neither of the two studies presented data on fungi. This phenomenon can be attributed largely to the fact that at this stage fungal sequences are generally found to account for only a small proportion of all the sequences in metagenomic libraries of various samples, which limits our ability to uncover the functional potentials of soil fungal communities via metagenomics (Cuadros-Orellana et al., 2013; Sun and Badgley, 2019). In this context, we took advantage of the Illumina HiSeq 2500 (a widely used nextgeneration sequencing platform; Goodwin et al., 2016) to sequence fungal ITS2 region to get some clues for a better understanding of the responses of soil fungal communities to revegetation. To that end, $4000 \mathrm{~m}^{2}$ of vegetation was reestablished on an extremely acidic $(\mathrm{pH} 2.5) \mathrm{Cu}$ mine tailings pond with the use of eight plant species (including four grasses, two legumes, one non-grass herb and one nonlegume forb) and 120 soil fungal communities at three types of habitats in the revegetated mine wasteland were characterized. To our knowledge, this is the first in-depth analysis and comparison ofthe soil fungal communities at different habitats in a revegetated highly acidic mine wasteland. Given that only nine fungal species belonging to Acidea, Acidiella, Acidomyces, Acidothrix, Coniochaeta, Hortaea and Soosiella have been isolated from extremely acidic $(\mathrm{pH}<3)$ environments (Hujslová et al., 2017), we hypothesized that the fungal communities of unrevegetated habitat in the highly acidic mine wasteland were dominated by certain abovementioned genera and that contrasting fungal communities could occur at different habitats of the revegetated mine wasteland.

\section{Materials and methods}

\subsection{Site description and revegetation scheme}

This study was conducted at a Cu mine tailings pond located in the Chengmenshan $\mathrm{Cu}$ Mine of Jiujiang City, Jiangxi Province, China $\left(29^{\circ} 40^{\prime} 52^{\prime \prime} \mathrm{N}, 115^{\circ} 49^{\prime} 21^{\prime \prime} \mathrm{E}\right)$. The study site is characterized by a subtropical humid monsoon climate, with a mean annual precipitation of $1426 \mathrm{~mm}$ and a mean annual temperature of $17.0^{\circ} \mathrm{C}$ (Jiujiang Statistical Bureau, 2018). The tailings pond has been abandoned since 2006. A field survey before the implementation of our revegetation scheme showed that the surface tailings of the pond had an extremely low $\mathrm{pH}$ value (2.5) and contained excessive levels of heavy metals (see Yang et al., 2017 for more details). In spring 2014, a revegetation scheme was implemented to revegetate an area of $4000 \mathrm{~m}^{2}$ located at the center of the tailings pond, in which a direct revegetation strategy was employed as described in detail elsewhere (Yang et al., 2017). Briefly, ameliorants (lime: $20 \mathrm{t} \mathrm{ha}^{-1}$; chicken manure: $40 \mathrm{t} \mathrm{ha}^{-1}$ ) were incorporated into the tailings two months before planting at a depth of $10 \mathrm{~cm}$ to improve substrate conditions for plant growth and a mixture of eight plant species (including Artemisia capillaris, Cynodon dactylon, Boehmeria nivea,
Festuca arundinacea, Panicum repens, Paspalum notatum, Robinia pseudoacacia and Sesbania cannabina) was grown on the amended tailings from seeds or seedlings. Four grasses were included to quickly stabilize the bare soil surfaces and two legumes were planted to improve the soil $\mathrm{N}$ cycling (Tordoff et al., 2000; Mendez and Maier, 2008). The revegetated area consisted of 20 plots, each $5 \mathrm{~m} \times 40 \mathrm{~m}$. These plots were separated from each other by 1-m-width walk-ways (Figure S1; Tilman et al., 1996).

\subsection{Soil sampling}

As described previously by Yang et al. (2017), the vegetation cover of the revegetated area reached nearly $100 \%$ within only 6 months after the implementation of the revegetation scheme. The responses of the soil bacterial community to the revegetation were apparent at the first year after implementation. In this study, however, we collected soil samples to characterize soil fungal communities at the third and fourth years after the implementation of the revegetation scheme (i.e., in July 2016 and 2017, respectively). The two major reasons for us to do so were as follows: (i) it has been criticized that most prior studies regarding revegetation of mine tailings were terminated after only 1-2 years (Mendez and Maier, 2008); and (ii) there is evidence that soil fungal communities tend to show a delayed response to revegetation as compared to the bacterial communities (Valentín-Vargas et al., 2014).

At each sampling date, the 20 revegetated plots were sampled. For each plot, one soil sample was collected from each of the following three types of habitats using a sterile stainless steel trowel: (i) the amended layer $(0-10 \mathrm{~cm})$ of the reclaimed tailings (ALRT); (ii) the unamended layer (11$20 \mathrm{~cm}$ ) of the reclaimed tailings (ULRT); and (iii) the nearby unreclaimed tailings (UT, considered as a surrogate of control habitat; Figure S1) at a depth of 0-10 cm. In sum, 120 soil samples were collected, as we had two sampling dates, three types of habitats and 20 replicates for each habitat type at each sampling date. The total plot area covered by these samples was approximately $960 \mathrm{~m}^{2}$. Because each of these samples was comprised of three independent subsamples that were collected randomly from three loci over an area of about four $\mathrm{m}^{2}$ and pooled, with those subsamples of ULRT and ALRT being collected from the same loci (but at different depths). During sampling, any visible roots and plant debris were removed with forceps. All samples were shipped frozen on dry ice to the laboratory where they were stored at $4^{\circ} \mathrm{C}$ and processed within two weeks.

\subsection{Soil physico-chemical analyses}

The following physico-chemical properties of the soil samples were analyzed using standard methods as described elsewhere (Yang et al., 2017): moisture content, redox potential (Eh), concentrations of ferric and ferrous iron, $\mathrm{pH}$, net acid generation capacity (NAG), NAG-pH, sulfate, total $\mathrm{C}$, total $\mathrm{N}$, total phosphorus $(P)$, available $P$, concentrations of total and 
diethylenetriaminepentaacetic acid (DTPA)-extractable heavy metals (including $\mathrm{Cd}, \mathrm{Cu}, \mathrm{Pb}$ and $\mathrm{Zn}$ ).

\subsection{Soil DNA extraction and sequencing}

Total genomic DNA of each soil sample (about $1 \mathrm{~g}$ ) was extracted with a commercial soil DNA isolation kit (FastDNA Spin kit, MP Biomedicals, Santa Ana, CA, USA) according to the manufacturer's protocol. DNA concentration and purity were evaluated using a NanoDrop 2000 spectrophotometer (Thermo Scientific, Waltham, MA, USA). To generate highly replicable results, a nested PCR approach as described by Davey et al. (2012) was employed to amplify the ITS2 region of fungi. The entire ITS region of fungal DNA was first amplified using the fungal-specific primers ITS1F (5'-CTTGGTCATTTAGAGGAAGTAA-3') and ITS4R (5'-TCCTCCGCTTATTGATATGC- $3^{\prime}$ ), and then a second $P C R$ using the primers ITS3F (5'-GCATCGATGAAGAACGCAGC- ${ }^{\prime}$ ) and ITS4R targeted the ITS2 region. The PCR products were purified using resin columns (Qiagen, Valencia, CA, USA) and were subsequently sequenced on the Illumina HiSeq platform (PE2500, Illumina, San Diego, CA, USA).

\subsection{Sequences processing}

Raw pair-end sequences resulting from HiSeq 2500 sequencing were treated with Mothur (Schloss et al., 2009) and QIIME (Caporaso et al., 2010). Chimeras were identified and removed using UCHIME (Edgar et al., 2011) implemented in Mothur. Reads with ambiguous bases were discarded using QIIME. Sequences were then assigned to each sample by the specific barcodes. The good-quality sequences (average quality score of the read $>25$ evaluated by QIIME) were clustered into operational taxonomic units (OTUs) at the $97 \%$ identity threshold using the UCLUST algorithm. The most abundant sequence in each cluster was designated as the representative sequence of each OTU. Taxonomic assignment of the OTUs was performed with 0.8 cut-off settings based on the RDP classifier (Wang et al., 2007) against the UNITE reference data set (version 7.0; Kõljalg et al., 2013). The OTUs with only one sequence (singletons) and those that were not assigned to the fungal kingdom were discarded. To compensate for the uneven sequencing efforts of different samples, a resampling step was performed using Mothur to randomly select the same number of sequence (26991) per sample. Alpha diversity was estimated by five indices including OTU number, Chao1, ACE, Simpson and Shannon. Both the richness estimators (i.e. OTU number, ACE and Chao1) and diversity indices (i.e. Shannon and Simpson, which combine richness and evenness) were calculated using the 'vegan' package (Oksanen et al., 2015) in R 3.3.1. The beta diversity (reflected by Bray-Curtis distance) metrics of fungal communities were also calculated with the 'vegan' package. The sequences reported in this paper have been deposited in the European Nucleotide Archive database (accession No. PRJEB30267).
2.6 Data analysis

CANOCO software (version 5.02, Microcomputer Power, Ithaca, NY, USA), R programs (https://www.r-project.org/) and SPSS 22.0 software (SPSS, Inc., Chicago, USA) were used for data analysis. We first performed Shapiro-Wilk normality test for checking ANOVA assumptions. The results showed that for some groups of our data, the assumptions for ANOVA were not met. Therefore, we used Kruskal-Wallis rank sum test instead of ANOVA. After confirming that the Kruskal-Wallis test was significant, Nemenyi test was further performed to determine which levels of the individual variables differed between different habitat types. Uni-Frac principal coordinate analysis (PCOA) based on OTUs, followed by ADONIS test, was performed to provide an overview of the differences between habitat types in the total soil fungal community composition. Bio-Env (Clarke and Ainsworth, 1993) was employed to identify the most influential soil physico-chemical properties affecting the fungal community composition (at OTU level). Pearson correlation coefficients were calculated between the soil physico-chemical properties selected by the Bio-Env analysis mentioned above and the fungal community characteristics (including alpha diversity metrics, the relative abundances of dominant phyla and genera). For each fungal community characteristic, the soil physico-chemical property found to have a maximum Pearson correlation coefficient (absolute value) was considered as the most important predictor of that characteristic. Redundancy analysis (RDA) was also performed to link fungal community composition (at OTU level) to environmental factors, as detrended correspondence analysis showed that the largest axis length was less than three.

\section{Results}

\subsection{Soil physico-chemical properties}

At 3 years after the vegetation cover was re-established, neutral $\mathrm{pH}$ was recorded not only at ALRT but also at ULRT, while UT still remained extremely acidic $(\mathrm{pH} 2.9$; Table 1$)$. This was accompanied by a significantly $(P<0.05)$ enhanced NAG-pH at both ALRT and ULRT (Table 1). The concentrations of total $\mathrm{C}$, total $\mathrm{N}$, total $\mathrm{P}$ and available $\mathrm{P}$ differed significantly $(P<0.05)$ between the three habitat types, with those at ALRT being the highest (Table 1). On the other hand, the EC values at ALRT and ULRT were significantly $(P<0.05)$ lower than that of UT. A similar pattern was observed for Eh, $\mathrm{NAG}$, the concentrations of $\mathrm{Fe}^{3+}, \mathrm{SO}_{4}{ }^{2-}$, DTPA-extractable $\mathrm{Cu}$ and $\mathrm{Zn}$ (Tables 1 and S1). The differences between the three habitat types were also found at four years after the vegetation cover was re-established, although the temporal changes of soil physico-chemical properties for any habitat type were not obvious within the time frame of this study (Tables 1 and S1). 
Table 1 Selected soil physico-chemical properties $(n=20$; mean \pm s.e. $)$ of the three habitats at three and four years after the initiation of the revegetation scheme.

\begin{tabular}{|c|c|c|c|c|c|c|}
\hline & \multicolumn{3}{|l|}{ Three years } & \multicolumn{3}{|l|}{ Four years } \\
\hline & $\mathrm{UT}^{\mathrm{a}}$ & ULRT & ALRT & UT & ULRT & ALRT \\
\hline $\mathrm{pH}$ & $2.9 \pm 0.05 b^{b}$ & $7.0 \pm 0.25 \mathrm{a}$ & $6.9 \pm 0.08 \mathrm{a}$ & $2.7 \pm 0.03 \mathrm{~b}$ & $6.5 \pm 0.23 \mathrm{a}$ & $7.3 \pm 0.04 \mathrm{a}$ \\
\hline Eh $(m V)$ & $619 \pm 5.5 \mathrm{a}$ & $349 \pm 22 b$ & $257 \pm 4.6 \mathrm{c}$ & $608 \pm 14 a$ & $394 \pm 24 b$ & $203 \pm 5.1 c$ \\
\hline $\mathrm{EC}\left(\mathrm{mS} \mathrm{cm} \mathrm{cm}^{-1}\right)$ & $0.82 \pm 0.07 \mathrm{a}$ & $0.48 \pm 0.04 \mathrm{~b}$ & $0.36 \pm 0.01 \mathrm{c}$ & $0.85 \pm 0.05 a$ & $0.40 \pm 0.04 \mathrm{~b}$ & $0.37 \pm 0.01 \mathrm{~b}$ \\
\hline $\mathrm{NAG}\left(\mathrm{kg} \mathrm{H}_{2} \mathrm{SO}_{4} \mathrm{t}^{-1}\right)$ & $25 \pm 1.2 \mathrm{a}$ & $3.6 \pm 0.79 b$ & $0.62 \pm 0.31 \mathrm{c}$ & $30 \pm 0.93 a$ & $2.7 \pm 0.32 \mathrm{~b}$ & $1.0 \pm 0.49 b$ \\
\hline NAG-pH & $2.6 \pm 0.02 b$ & $6.1 \pm 0.26 \mathrm{a}$ & $7.2 \pm 0.17 \mathrm{a}$ & $2.6 \pm 0.01 \mathrm{c}$ & $6.1 \pm 0.18 b$ & $7.2 \pm 0.18 \mathrm{a}$ \\
\hline $\mathrm{SO}_{4}{ }^{2-}\left(\mathrm{g} \mathrm{kg}^{-1}\right)$ & $33 \pm 6.1 \mathrm{a}$ & $13 \pm 2.2 \mathrm{a}$ & $2.9 \pm 0.30 \mathrm{~b}$ & $37 \pm 6.4 \mathrm{a}$ & $15 \pm 2.2 \mathrm{a}$ & $2.2 \pm 0.17 \mathrm{~b}$ \\
\hline $\mathrm{Fe}^{2+}\left(\mathrm{g} \mathrm{kg}^{-1}\right)$ & $1.3 \pm 0.22 b$ & $13 \pm 1.8 \mathrm{a}$ & $6.8 \pm 0.85 a$ & $1.9 \pm 0.45 c$ & $11 \pm 1.8 \mathrm{a}$ & $4.2 \pm 0.44 \mathrm{~b}$ \\
\hline $\mathrm{Fe}^{3+}\left(\mathrm{g} \mathrm{kg}^{-1}\right)$ & $27 \pm 3.4 \mathrm{a}$ & $18 \pm 2.6 \mathrm{a}$ & $4.7 \pm 2.6 \mathrm{~b}$ & $29 \pm 3.0 \mathrm{a}$ & $16 \pm 2.5 \mathrm{~b}$ & $4.1 \pm 0.50 \mathrm{c}$ \\
\hline Total C $\left(\mathrm{g} \mathrm{kg}^{-1}\right)$ & $1.3 \pm 0.07 \mathrm{c}$ & $3.8 \pm 0.49 \mathrm{~b}$ & $90 \pm 3.5 \mathrm{a}$ & $1.2 \pm 0.10 \mathrm{c}$ & $3.1 \pm 0.21 \mathrm{~b}$ & $79 \pm 5.6 \mathrm{a}$ \\
\hline Total $\mathrm{N}\left(\mathrm{mg} \mathrm{kg}^{-1}\right)$ & $172 \pm 4.4 \mathrm{c}$ & $352 \pm 27 \mathrm{~b}$ & $8107 \pm 311 a$ & $205 \pm 19 c$ & $338 \pm 17 b$ & $7054 \pm 491 \mathrm{a}$ \\
\hline Total $\mathrm{P}\left(\mathrm{mg} \mathrm{kg}^{-1}\right)$ & $102 \pm 11 \mathrm{c}$ & $331 \pm 34 b$ & $907 \pm 100 \mathrm{a}$ & $95 \pm 11 \mathrm{c}$ & $287 \pm 30 \mathrm{~b}$ & $796 \pm 84 a$ \\
\hline Available $\mathrm{P}\left(\mathrm{mg} \mathrm{kg}^{-1}\right)$ & $3.2 \pm 1.5 \mathrm{c}$ & $27 \pm 5.0 \mathrm{~b}$ & $73 \pm 7.2 \mathrm{a}$ & $3.0 \pm 1.2 b$ & $31 \pm 4.3 \mathrm{a}$ & $53 \pm 3.7 \mathrm{a}$ \\
\hline Moisture content (\%) & $13 \pm 0.82 b$ & $11 \pm 0.74 b$ & $21 \pm 2.5 \mathrm{a}$ & $14 \pm 1.1 \mathrm{~b}$ & $17 \pm 0.68 b$ & $34 \pm 1.4 \mathrm{a}$ \\
\hline
\end{tabular}

a UT, the unreclaimed tailings; ULRT, unamended layer of the reclaimed tailings; ALRT, amended layer of the reclaimed tailings.

${ }^{b}$ Data for samples of different habitat types collected at a given sampling date with different letters are significantly different from each other $(P<0.05$, Nemenyi test).

\subsection{Soil fungal diversity and community composition}

In this study, a total of 6569678 high quality fungal sequences were obtained, representing 3323 OTUs. After resampling, the average number of fungal OTUs for the three habitat types ranged from 137 to 407 (Table 2). At both sampling dates, the fungal OTU numbers followed the ascending order of UT < ULRT < ALRT $(P<0.05$; Table 2). Similar patterns were also recorded for other alpha diversity metrics (i.e. Chao1, ACE, Shannon and Simpson indices), although the differences between UT and ULRT in certain alpha diversity metrics (e.g. Simpson index) were not statistically significant $(P>0.05)$ at four years (Table 2). Little variation in fungal diversity of a given habitat type was observed between the two sampling dates.

The fungal communities across all samples were primarily dominated by the phylum Ascomycota, with an average relative abundance ranging from $74.5 \%$ to $98.4 \%$ (Fig. 1). Regardless of the time of sampling, the relative abundances of Ascomycota at ALRT were significantly $(P<0.05)$ lower than those of ULRT and UT. An opposite trend was found for Basidiomycota, the second-most dominant phylum at ALRT (Fig. 1). Other dominant phyla (referring to those with an average relative abundance $>1 \%$ ) in our samples included Rozellomycota, Mortierellomycota, Chytridiomycota, Glomeromycota, Blastocladiomycota and Aphelidiomycota (Fig. 1).

At three years after the vegetation cover was re-established, the two most abundant genera at UT were Acidomyces and Acidiella, supporting our hypothesis regarding dominant fungal genera in the mine wasteland. Their relative abundances were significantly $(P<0.05)$ higher at UT than at ULRT and ALRT (Fig. 2A). Although little temporal variation in the relative abundance of the two genera was observed for any habitat type $(P>0.05$, Fig. 2$)$, their dominance at UT at four years after the vegetation cover was re-established became inferior to that of an unclassified Sordariomycetes genus (Fig. 2B). At both sampling dates, Trichoderma and Talaromyces were numerically the most dominant genera at ULRT, with relative abundances being significantly $(P<0.05)$ higher than those of not only UT but also ALRT (Fig. 2). At three years

Table 2 Alpha diversity metrics $(n=20$; mean \pm s.e.) of soil fungi at the three habitats at three and four years after the initiation of the revegetation scheme.

\begin{tabular}{|c|c|c|c|c|c|c|}
\hline & \multicolumn{3}{|l|}{ Three years } & \multicolumn{3}{|l|}{ Four years } \\
\hline & $\mathrm{UT}^{\mathrm{a}}$ & ULRT & ALRT & UT & ULRT & ALRT \\
\hline NO. of OTUs & $172 \pm 5.1 c^{b}$ & $290 \pm 15 b$ & $407 \pm 11 \mathrm{a}$ & $137 \pm 1.9 \mathrm{c}$ & $193 \pm 12 b$ & $393 \pm 11 a$ \\
\hline Chao1 & $304 \pm 7.7 \mathrm{c}$ & $447 \pm 18 b$ & $557 \pm 12 \mathrm{a}$ & $245 \pm 4.9 \mathrm{~b}$ & $304 \pm 15 b$ & $507 \pm 10$ a \\
\hline ACE & $379 \pm 13 c$ & $504 \pm 19 b$ & $590 \pm 13 a$ & $318 \pm 9.4 b$ & $355 \pm 17 b$ & $503 \pm 9.6$ a \\
\hline Shannon index & $0.82 \pm 0.13 c$ & $2.28 \pm 0.11 b$ & $3.28 \pm 0.14 \mathrm{a}$ & $1.05 \pm 0.10 \mathrm{~b}$ & $1.72 \pm 0.18 b$ & $3.36 \pm 0.13 \mathrm{a}$ \\
\hline Simpson index & $0.35 \pm 0.06 \mathrm{~b}$ & $0.78 \pm 0.02 a$ & $0.87 \pm 0.03 a$ & $0.47 \pm 0.05 b$ & $0.61 \pm 0.06 \mathrm{~b}$ & $0.88 \pm 0.02 \mathrm{a}$ \\
\hline
\end{tabular}

a UT, the unreclaimed tailings; ULRT, unamended layer of the reclaimed tailings; ALRT, amended layer of the reclaimed tailings.

${ }^{b}$ Data for samples of different habitat types collected at a given sampling date with different letters are significantly different from each other $(P<0.05$, Nemenyi test). 

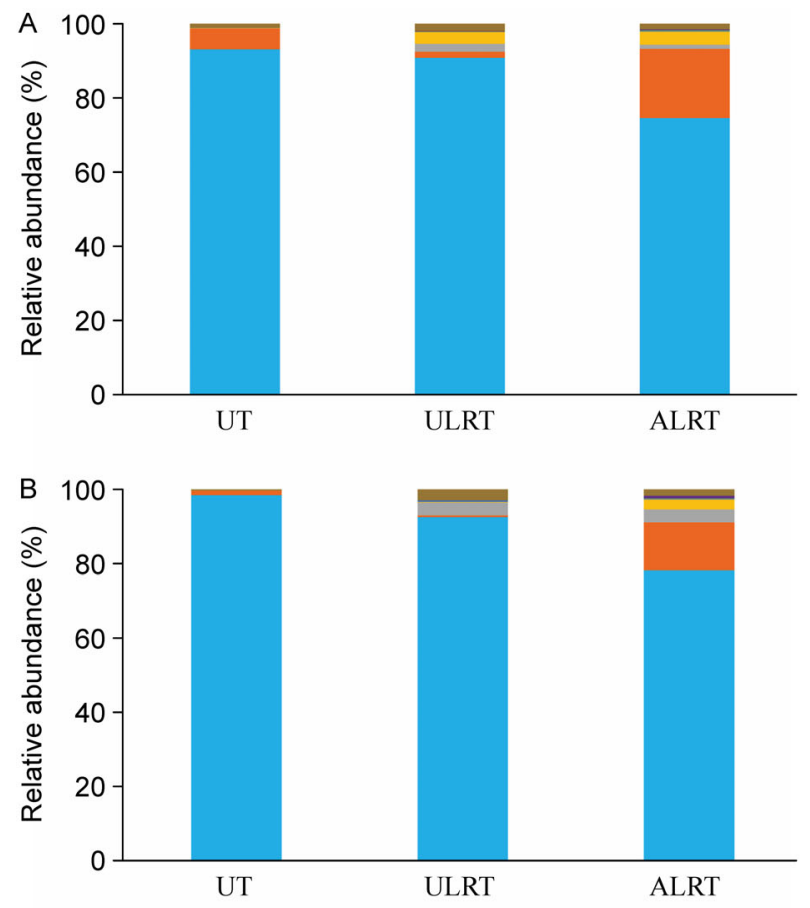

\begin{tabular}{|lll}
\hline Ascomycota & Basidiomycota & Rozellomycota \\
$\square$ Mortierellomycota & Chytridiomycota & Glomeromycota \\
$\square$ Blastocladiomycota & - Aphelidiomycota & Minor phyla \\
$\square$ Unclassified_fungi & &
\end{tabular}

Fig. 1 Relative abundance $(\%, n=20)$ of the dominant fungal phyla in the unreclaimed tailings (UT), unamended layer of the reclaimed tailings (ULRT) and amended layer of the reclaimed tailings (ALRT) at three (A) and four years $(B)$ after the initiation of the revegetation scheme. Those phyla with an average relative abundance of $<1 \%$ were classified as minor phyla. Unclassifiedfungi represented those that were not classifiable at phylum level.

after the vegetation cover was re-established, ULRT had a significantly $(P<0.05)$ higher relative abundance of Penicillium (the third most dominant genus) compared to UT (Fig. 2A). As time progressed, the relative abundance of Penicillium at ULRT also exceeded that of ALRT (Fig. 2B). Additionally, the most abundant genus at ALRT at both sampling dates was an unclassified Microascales genus, which was followed by Penicillium, Lycoperdon, Scopulariopsis (Fig. 2).

At three years after the vegetation cover was re-established, the majority of ULRT fungal communities were separated from those of UT and ALRT by PCoA axis PC1; while almost all UT fungal communities were distinguished from those of ALRT by PCoA axis PC2 (Fig. 3A). As time progressed, all UT fungal communities were separated from those of ALRT by PCoA axis PC1. All ULRT fungal communities were distinguished from those of UT and ALRT by PCoA axis PC2 (Fig. 3B). These results were in line with our hypothesis about contrasting overall some fungal community composition between different habitat types.
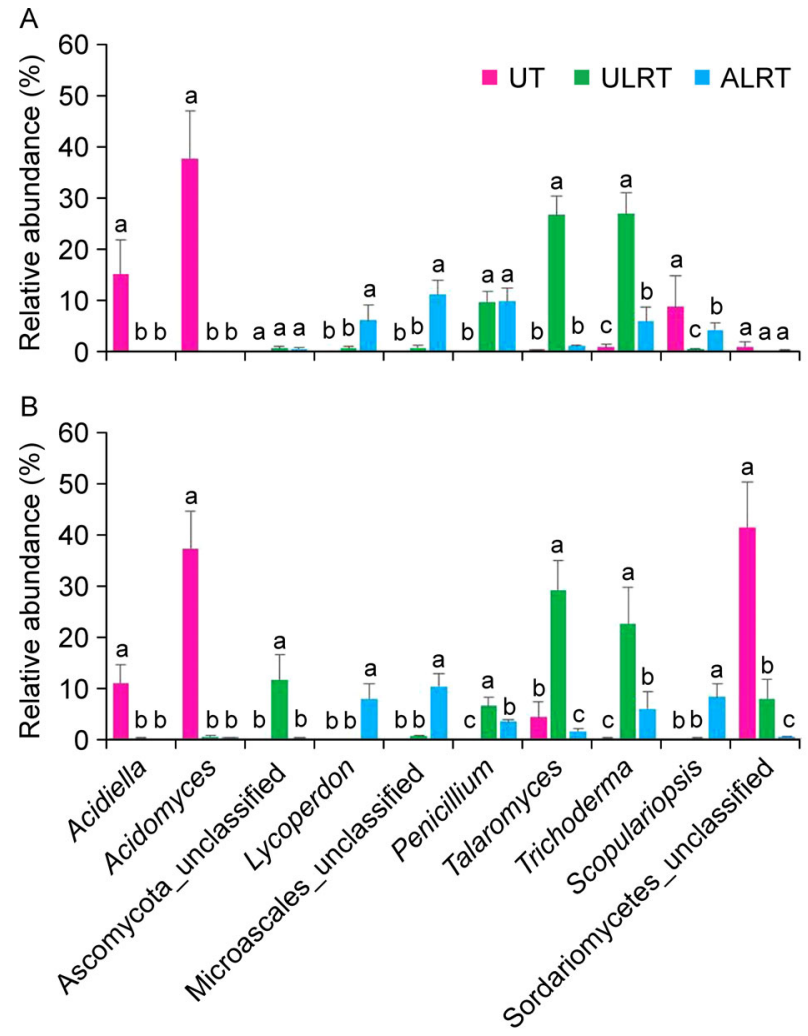

Fig. 2 Relative abundance (\%,n=20) of the dominant fungal genera in the unreclaimed tailings (UT), unamended layer of the reclaimed tailings (ULRT) and amended layer of the reclaimed tailings (ALRT) at three (A) and four years $(B)$ after the initiation of the revegetation scheme. Those phyla with an average relative abundance of $>1 \%$ were classified as dominant phyla. Different letters above the bars within the same genus group indicate a significant difference between habitat types at $5 \%$ significance level according to Nemenyi test.

3.3 Links between soil physico-chemical properties and fungal community characteristics

A subset of four and three soil physico-chemical properties was selected by the Bio-Env analysis as the most influential factors affecting the soil fungal community composition at the two sampling dates (Table 3). Among them, DTPA-Zn and $\mathrm{Cu}-$ related properties were shared by both sampling dates. More specifically, DTPA-Zn alone explained $5.8 \%$ and $3.3 \%$ of the total variation in the fungal community composition observed at the two sampling dates (Table 3). DTPA-Cu was found to be the most important predictor of a predominant portion of other fungal community characteristics taken into account in this study (Tables S2-S4). There was a positive linear relationship $(P<0.001)$ between the concentration of DTPA-Cu and the relative abundance of Acidomyces at the two sampling dates ( $r=0.52$ and $r=0.54$; Fig. 4). In addition, the results of RDA showed that total $C$ and NAG were the major determinants of fungal community composition at both three and four years after initiation of the revegetation scheme (Figure S2). 


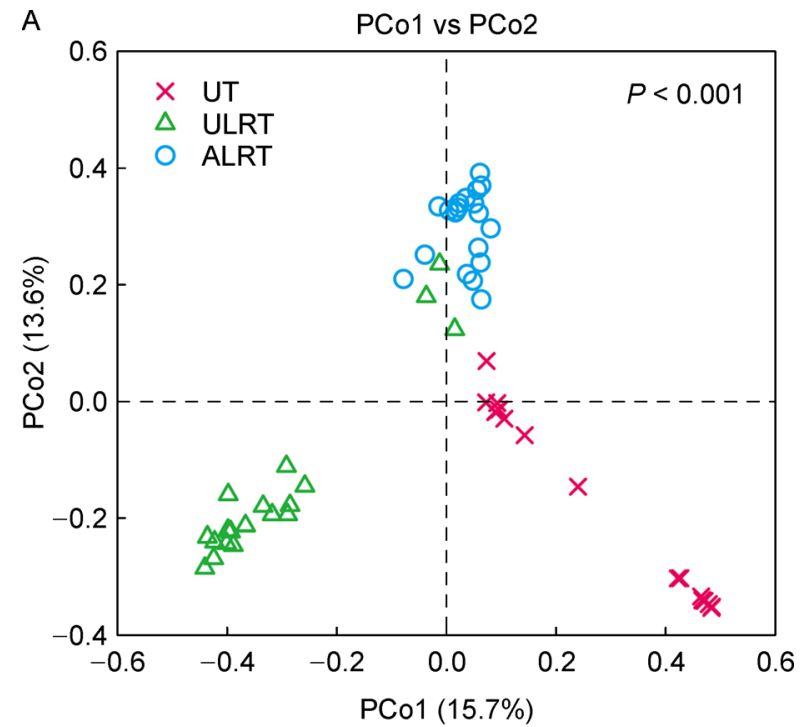

B

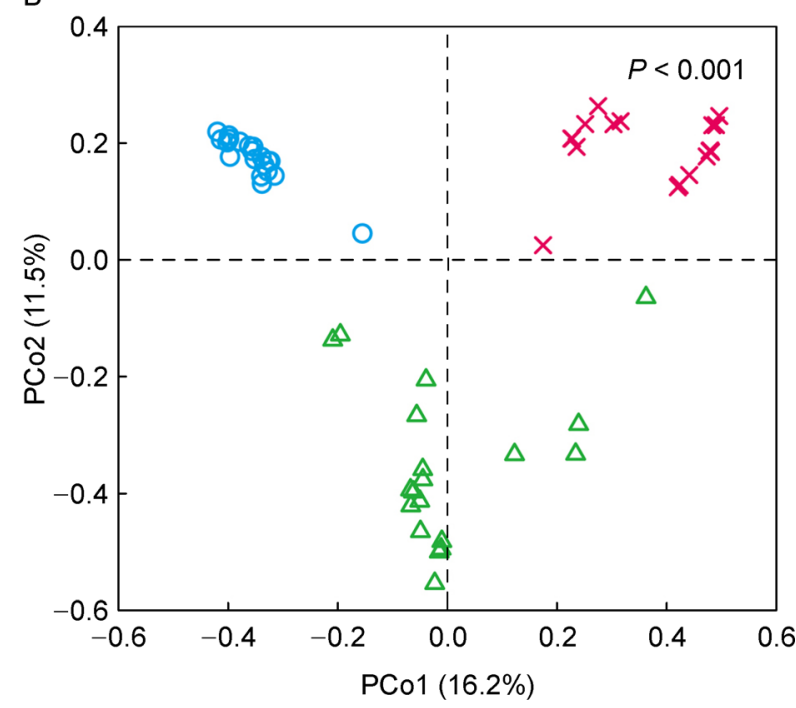

Fig. 3 Ordination plots of PCoA results for the overall soil fungal community composition (at OTU level) of UT, ULRT and ALRT at three $(A)$ and four years $(B)$ after the initiation of the revegetation scheme. The results of ADONIS test are shown.

However, the variances explained by the two environmental factors (e.g. total $\mathrm{C}$ explained $<2.3 \%$ of the total variance; Table S5) were generally smaller than those explained by the environmental factors identified by the Bio-Env procedure (Table 3).

\section{Discussion}

Direct revegetation strategies that attempt to construct a root zone (i.e. a layer amended with substrate ameliorants) directly in mine wastelands through remediation measures have received increasing interest in the past several years (Huang et al., 2012). However, there are few published assessments of direct revegetation of mine wastelands based
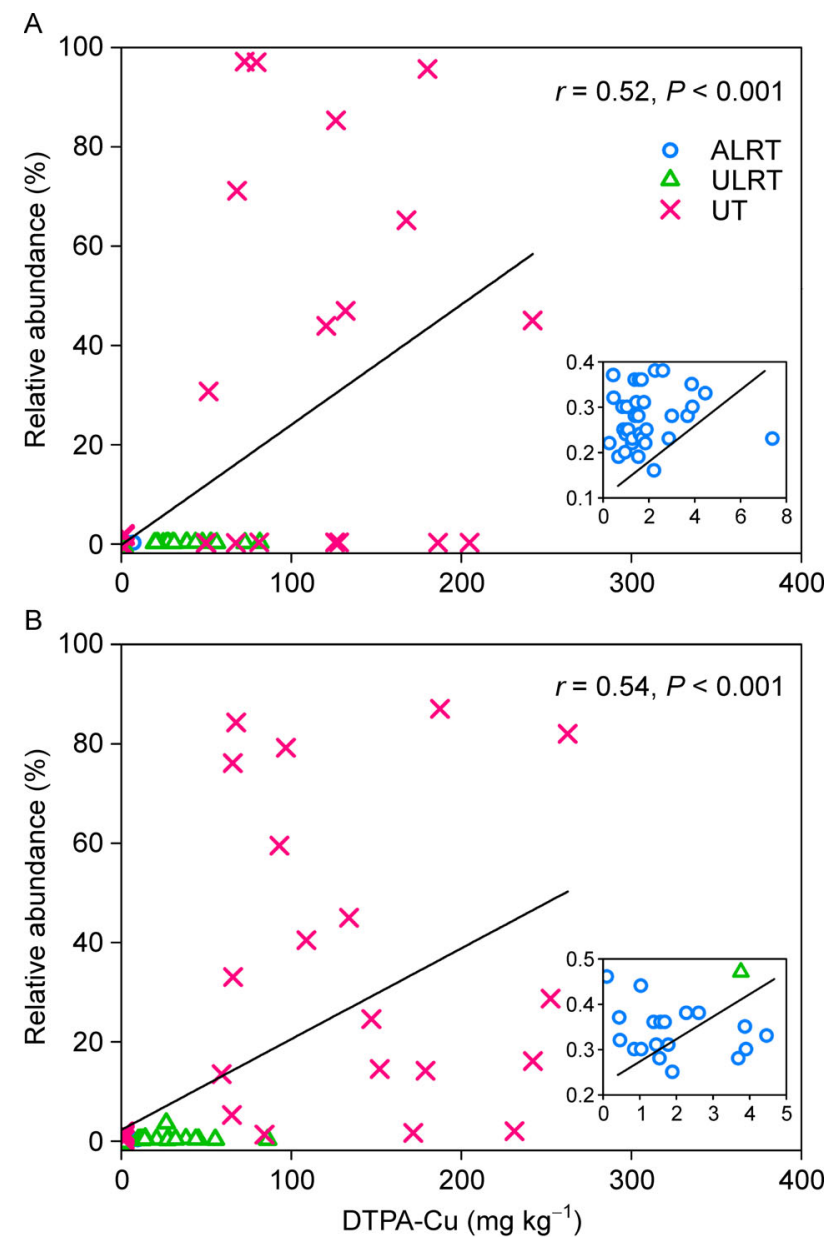

Fig. 4 Linear regression relationships between the concentration of DTPA-Cu and the relative abundance of Acidomyces in the soil samples collected from the three habitats at three $(A)$ and four years $(B)$ after the initiation of the revegetation scheme. The data points that were highly overlapped in the lower left corners of the main figures are shown in the inserts.

Table 3 Effects of the subset of physico-chemical properties of soil samples selected by the Bio-Env procedure on the overall fungal community composition (at the OTU level) of the three habitats at three and four years after the initiation of the revegetation scheme.

\begin{tabular}{llll}
\hline & Variation explained & Pseudo-F & $P$-value \\
\hline Three years & & & \\
DTPA-Zn & $5.8 \%$ & 3.7 & 0.001 \\
Total $\mathrm{Cu}$ & $1.9 \%$ & 1.2 & 0.22 \\
$\mathrm{Fe}^{2+}$ & $1.9 \%$ & 1.2 & 0.24 \\
Total Zn & $1.9 \%$ & 1.2 & 0.24 \\
Total & $14.4 \%$ & 3.7 & 0.001 \\
Four years & & & \\
EC & $6.2 \%$ & 4.3 & 0.001 \\
DTPA-Zn & $3.3 \%$ & 2.4 & 0.03 \\
DTPA-Cu & $1.9 \%$ & 1.3 & 0.20 \\
Total & $13.5 \%$ & 2.8 & 0.004 \\
\hline
\end{tabular}


on data from large-scale field trials lasting longer than two years (but see Roseby et al., 1998; Bendfeldt et al., 2001; Shukla et al., 2005; Mulligan et al., 2006). It is important to note that the third year should be an important time point to assess the effectiveness of a direct revegetation scheme. This is because after two years almost all plant roots have completely penetrated an amended layer and have begun to penetrate into the hostile substrate conditions in the unamended layer of mine wastelands. Such a plant 'adaptation' process is expected to be associated with remarkable changes in the soil fungal community (Huang et al., 2012). Our ongoing monitoring program has shown that the $4000 \mathrm{~m}^{2}$ of vegetation cover that we established on an extremely acidic $\mathrm{Cu}$ mine tailings pond (Yang et al., 2017) has not only survived, but thrived at four years after the initiation of the revegetation scheme. We therefore believe that this largescale field trial has provided an exceptional opportunity to shed some light on the effectiveness of a direct revegetation scheme in terms of the responses of soil fungal communities to revegetation of mine wastelands.

Revegetation is presumed to enhance soil fungal diversity of target mine wastelands by various mechanisms, such as increasing the diversity of microhabitats and food resources (Kardol and Wardle, 2010). However, only two previous studies have explicitly addressed the effects of revegetation on the soil fungal diversity of mine wastelands. The first was based on a field trial conducted with an indirect revegetation strategy, showing that the revegetation scheme increased the counts of colony-forming units of fungi in the mine soil (Dos Santos et al., 2013). The second revealed that the number of DGGE bands for soil fungi was significantly higher in the mine tailings mesocosms developed with a direct revegetation strategy than in the control (i.e. the tailings only; ValentínVargas et al., 2014). In agreement with these previous findings, we observed that the alpha diversity metrics (both richness and evenness) of fungi considered in this study were significantly higher at ALRT than at UT (Table 2). More importantly, the fungal diversity at ULRT was also significantly higher than UT, indicating that the plant roots were able to exert beneficial effects on soil fungi in the unamended layer of the tailings pond while they were struggling to penetrate and establish in it. It is notable however, that the soil fungal diversity was still lower at ULRT than at ALRT even at four years after the initiation of the revegetation scheme (Table 2). This result could be attributed largely to the higher concentration of DTPA-Cu in ULRT compared to that in ALRT (Table S1), given that DTPA-Cu was the most important predictor of fungal diversity (Table S2). Nonetheless, the less diverse fungal communities at ULRT than at ALRT were likely a reflection of the delayed responses of the fungal community to revegetation than the bacterial community (Valentín-Vargas et al., 2014). Our previous study showed that there were no significant differences between ULRT and ALRT in bacterial diversity at one year after the initiation of the revegetation scheme (Yang et al., 2017). One possible reason for the delayed 'responses' of the fungal communities is a reported inferior ability of fungi to tolerate heavy metals in mine soils compared to bacteria (Pennanen et al., 1996). Another possible explanation is that the growth and turn-over times of fungi are generally slower than that of bacteria, as fungi take time to develop colonies (Rousk et al., 2010).

The phylum Ascomycota dominated all fungal communities of the three types of habitats (Fig. 1), which was consistent with a recent study showing that the fungal community of an aged heavy metal-contaminated soil from a coking plant wasteland was composed mainly of Ascomycota (with a relative abundance of 53.6\%; Bourceret et al., 2016). In fact, dominance of Ascomycota in fungal communities has been also reported for a range of uncontaminated environments (Nemergut et al., 2008; Xu et al., 2012; Yao et al., 2017). A reasonable explanation for the dominance of Ascomycetes in these diverse uncontaminated environments is that Ascomycota represent the only group of eukaryotes that manifest incredible diversity in their lifestyles and metabolic capacities (Whiteway et al., 2015). Despite this, the relative abundances of Ascomycota at UT and ULRT (>90\%, Fig. 1) were unusually high as compared to those reported in the literature. Such an unusual prevalence of Ascomycota has two implications, although it is difficult at this stage to clearly identify the underlying reasons. On the one hand, the exceptionally high relative abundances of Ascomycota at UT $(\mathrm{pH}<3)$ indicated that Ascomycota had greater tolerance to acidic environments than other fungal phyla, in spite of the potential ability of fungi to thrive in a wider $\mathrm{pH}$ range than bacteria (Rousk et al., 2010). In line with this notion, Baker et al. (2004) found that all the fungal sequences retrieved from extremely acidic $(\mathrm{pH}<1)$ subsurface acid mine drainage solutions at Iron Mountain in the USA belonged to Ascomycota. On the other hand, no significant differences between near-neutral ULRT and extremely acidic UT (Table 1) in Ascomycota's prevalence (Fig. 1) suggested a minor role of $\mathrm{pH}$ in determining the relative abundance of this phylum. Indeed, we found that DTPA-Cu rather than $\mathrm{pH}$ was the most important predictor of the relative abundance of Ascomycota (Pearson correlation coefficients $\geqslant 0.42, P<0.01$; Table S3). In this context, it is easy to understand why the lowest relative abundances of Ascomycota were observed at ALRT containing the lowest concentrations of DTPA-Cu (Fig. 1 and Table S1). Remarkably, the prevalence of Ascomycota at ALRT was at a level similar to that reported for some uncontaminated arable soils (Nemergut et al., 2008; Yao et al., 2017). It was also interesting to note that the relative abundances of Basidiomycota at ALRT (approximately 15\%, Fig. 1) were comparable to those observed in some uncontaminated arable soils (Nemergut et al., 2008; Yao et al., 2017), as most decomposers of lignocellulose in plant litter are affiliated with this phylum (Lundell et al., 2010).

Among the three most dominant genera observed in UT fungal communities (Fig. 2), Acidomyces and Acidiella are two recently proposed genera (Baker et al., 2004; Hujslová et al., $2013,2017)$. The four currently recognized species of the two genera were isolated from extremely acidic $(\mathrm{pH}<3)$ habitats, 
accounting for approximately $50 \%$ of all fungal species known to exclusively inhabit extremely acidic environments (Hujslová et al., 2017). Although there are very few (if any) reports on the relative abundances of the two genera in fungal communities in any habitat, their predominance in UT fungal communities is remarkable. This is especially the case for Acidomyces whose relative abundance could be as high as approximately $38 \%$ on average (Fig. 2). A similar high relative abundance was also observed for an unclassified genus of Sordariomycetes in UT (Fig. 2B), supporting the notion that extremely acidic habitats harbour higher fungal diversity than previously appreciated and thus are good targets for bioprospecting (Hujslová et al., 2017). Unexpectedly, the relative abundance of Acidomyces was positively related to the concentration of DTPA-Cu (Fig. 4 and Table S4), indicating strong $\mathrm{Cu}$ tolerance of this genus. Nonetheless, Acidomyces were very subordinate in fungal communities at ULRT and ALRT, with relative abundance being no greater than $0.5 \%$ (Fig. 2). One major reason for such dramatic decreases is likely that the concentrations of DTPA-Cu in the ULRT and ALRT were greatly decreased by revegetation (Table S1). Additionally, the increase in soil $\mathrm{pH}$ was probably another important reason, as the majority of known species in Acidomyces are acidophilic (Hujslová et al., 2017). In consistence with this notion, the relative abundance of Acidomyces was found to negatively correlate to soil $\mathrm{pH}$ $(P<0.001$; Pearson correlation coefficients: -0.562 and -0.648 for three and four years, respectively).

As to the dominant genera at ULRT and ALRT (Fig. 2), Trichoderma and Penicillium are well known for the abilities of some of their members to promote plant growth (Whitelaw, 1999; Harman et al., 2004). There is increasing evidence that some species of Talaromyces play an important role in the degradation of lignocellulosic biomass and have the potential to be used as a biofertilizer (Yilmaz et al., 2014; de Goes et al., 2017), while the co-occurrence of Talaromyces and Penicillium in a wide range of habitats has long been recognized (Pitt et al., 2000). The relative abundances of the three genera at ULRT and ALRT were remarkably high as compared to those reported for black soils (Mollisols) in PR China (Liu et al., 2015), indicating that their roles in promoting plant growth may be more pronounced in hostile habitats. Notably, the relative abundances of the three genera at ULRT at four years after the initiation of the revegetation scheme were higher than those of not only UT but also ALRT (Fig. 2B). There are two possible reasons for this. First, the concentrations of DTPA-Zn in ULRT were the lowest among the three types of habitats $(P<0.05$; Table S1), whereas DTPA-Zn was generally the most important predictor of the relative abundances of the three genera (negative relationships, $P<0.05$; Table S4). Secondly, the majority of root tips (physiologically active) were found to reside in the ULRT where they require more beneficial soil fungal partners to acquire more nutrients (Tedersoo et al., 2003).

PCoA based on OTUs showed that the three types of habitats tended to differ from each other in terms of the overall fungal community composition, which became more pronounced as time progressed (Fig. 3). However, the overall fungal community composition at ULRT did not seem more similar to the 'desirable' fungal community composition at ALRT than did that of UT, even at four years after the initiation of the revegetation scheme (Fig. 3B). This pattern was inconsistent with that observed for the bacterial community at one year after the initiation of the revegetation scheme (Yang et al., 2017), providing more preliminary evidence (other than alpha diversity metrics shown in Table 2) on the delayed responses of soil fungi to the revegetation as compared to soil bacteria (Valentín-Vargas et al., 2014). Nonetheless, DTPA-Zn, EC, DTPA-Cu and total $\mathrm{Cu}$ were found to be the main factors determining the overall fungal community composition (Table 3 ), being in accordance with the observations that the eukaryotic (including fungal) communities in acid mine drainage and sediments $(\mathrm{pH}<3)$ are influenced mainly by the presence of heavy metals (Aguilera et al., 2006; Volant et al., 2016). Note also that the results of RDA lent some support to the notion that total $\mathrm{C}$ and $\mathrm{pH}$ had an unnegligible influence on soil fungal community composition at different habitats of the revegetated mine wasteland (Rousk et al., 2010; Liu et al., 2015).

\section{Conclusions}

In conclusion, our study revealed that contrasting fungal communities occurred at different types of habitats in a revegetated extremely acidic mine wasteland and that the decreases in concentrations of DTPA-Cu and DTPA-Zn were the main drivers of the differences between habitats in fungal community features. Given that the three types of habitats investigated in this study were influenced by revegetation at different degrees (ALRT>ULRT>UT), our findings shed some light on the fungal ecology of revegetated mine wastelands and had implications for further improvement of revegetation schemes for mine wastelands. For instance, our results indicated the possibility that enhancing the relative abundances of Talaromyces, Trichoderma and Penicillium might improve the performances of revegetation schemes. Nonetheless, amplicon sequence abundance may not necessarily reflect biological abundance, highlight the urgent need for more culture-based studies.

\section{Acknowledgments}

We thank Professor AJM Baker (Universities of Melbourne and Queensland, Australia, and Sheffield, UK) for his help in the improvement of this paper. This work was supported financially by the Key-Area Research and Development Program of Guangdong Province (No. 2019B110207001), the National Natural Science Foundation of China (Nos. 41622106, 41471257, 31600082 and 41603074) and the China Postdoctoral Science Foundation (Nos. 2018M640798 and 2019M652939). 


\section{Electronic supplementary material}

Supplementary material is available in the online version of this article at http://dx.doi.org/10.1007/s42832-020-0022-x and is accessible for authorized users.

\section{References}

Aguilera, A., Manrubia, S.C., Gómez, F., Rodríguez, N., Amils, R., 2006. Eukaryotic community distribution and its relationship to water physicochemical parameters in an extreme acidic environment, Rio Tinto (southwestern Spain). Applied and Environmental Microbiology 72, 5325-5330.

Ascher, J., Ceccherini, M.T., Landi, L., Mench, M., Pietramellara, G., Nannipieri, P., Renella, G., 2009. Composition, biomass and activity of microflora, and leaf yields and foliar elemental concentrations of lettuce, after in situ stabilization of an arseniccontaminated soil. Applied Soil Ecology 41, 351-359.

Baker, B.J., Lutz, M.A., Dawson, S.C., Bond, P.L., Banfield, J.F., 2004. Metabolically active eukaryotic communities in extremely acidic mine drainage. Applied and Environmental Microbiology 70, 6264 6271.

Bendfeldt, E.S., Burger, J.A., Daniels, W.L., 2001. Quality of amended mine soils after sixteen years. Soil Science Society of America Journal 65, 1736-1744.

Bourceret, A., Cébron, A., Tisserant, E., Poupin, P., Bauda, P., Beguiristain, T., Leyval, C., 2016. The bacterial and fungal diversity of an aged PAH-and heavy metal-contaminated soil is affected by plant cover and edaphic parameters. Microbial Ecology 71, 711724.

Caporaso, J.G., Kuczynski, J., Stombaugh, J., Bittinger, K., Bushman, F.D., Costello, E.K., Fierer, N., Peña, A.G., Goodrich, J.K., Gordon, J.I., Huttley, G.A., Kelley, S.T., Knights, D., Koenig, J.E., Ley, R.E., Lozupone, C.A., McDonald, D., Muegge, B.D., Pirrung, M., Reeder, J., Sevinsky, J.R., Turnbaugh, P.J., Walters, W.A., Widmann, J., Yatsunenko, T., Zaneveld, J., Knight, R., 2010. QIIME allows analysis of high-throughput community sequencing data. Nature Methods 7, 335-336.

Clarke, K.R., Ainsworth, M., 1993. A method of linking multivariate community structure to environmental variables. Marine Ecology Progress Series 92, 205-219.

Cuadros-Orellana, S., Leite, L. R., Smith, A., Medeiros, J. D., Badotti, F., Fonseca, P. L., Vaz1, A. B. M., Oliveira, G., Góes-Neto, A., 2013. Assessment of fungal diversity in the environment using metagenomics: a decade in review. Fungal Genomics \& Biology 3 , $1-13$.

Davey, M.L., Heegaard, E., Halvorsen, R., Ohlson, M., Kauserud, H., 2012. Seasonal trends in the biomass and structure of bryophyteassociated fungal communities explored by 454 pyrosequencing. New Phytologist 195, 844-856.

de Goes, K.C.G.P., da Silva, J.J., Lovato, G.M., lamanaka, B.T. Massi, F.P., Andrade, D.S., 2017. Talaromyces sayulitensis, Acidiella bohemica and Penicillium citrinum in Brazilian oil shale by-products. Antonie van Leeuwenhoek 110, 1637-1646.

Dos Santos, J.V., de Melo Rangel, W., Azarias Guimarães, A., Duque
Jaramillo, P.M., Rufini, M., Marra, L.M., Varón López, M., Pereira da Silva, M.A., Fonsêca Sousa Soares, C.R., de Souza Moreira, F. M., 2013. Soil biological attributes in arsenic-contaminated gold mining sites after revegetation. Ecotoxicology (London, England) 22, 1526-1537.

Dudka, S., Adriano, D.C., 1997. Environmental impacts of metal ore mining and processing: a review. Journal of Environmental Quality 26, 590-602.

Edgar, R.C., Haas, B.J., Clemente, J.C., Quince, C., Knight, R., 2011. UCHIME improves sensitivity and speed of chimera detection. Bioinformatics (Oxford, England) 27, 2194-2200.

Gastauer, M., Vera, M.P.O., de Souza, K.P., Pires, E.S., Alves, R., Caldeira, C.F., Ramos, S.J., Oliveira, G., 2019. A metagenomic survey of soil microbial communities along a rehabilitation chronosequence after iron ore mining. Scientific Data 6, 190008.

Goodwin, S., McPherson, J.D., McCombie, W.R., 2016. Coming of age: ten years of next-generation sequencing technologies. Nature Reviews. Genetics 17, 333-351.

Gordon, R.B., 2002. Production residues in copper technological cycles. Resources, Conservation and Recycling 36, 87-106.

Harman, G.E., Howell, C.R., Viterbo, A., Chet, I., Lorito, M., 2004. Trichoderma species-opportunistic, avirulent plant symbionts. Nature Reviews. Microbiology 2, 43-56.

Huang, L., Baumgartl, T., Mulligan, D., 2012. Is rhizosphere remediation sufficient for sustainable revegetation of mine tailings? Annals of Botany 110, 223-238.

Hujslová, M., Kubátová, A., Bukovská, P., Chudičková, M., Kolařík, M., 2017. Extremely acidic soils are dominated by species-poor and highly specific fungal communities. Microbial Ecology 73, 321-337.

Hujslová, M., Kubátová, A., Kostovčík, M., Kolařík, M., 2013. Acidiella bohemica gen. et sp. nov. and Acidomyces spp. (Teratosphaeriaceae), the indigenous inhabitants of extremely acidic soils in Europe. Fungal Diversity 58, 33-45.

Jiujiang Statistical Bureau, 2018. Statistical Yearbook of Jiujiang 2017. Jiujiang, China: Jiujiang Statistical Bureau.

Johnson, D.B., 2003. Chemical and microbiological characteristics of mineral spoils and drainage waters at abandoned coal and metal mines. Water, Air, and Soil Pollution 3, 47-66.

Kardol, P., Wardle, D.A., 2010. How understanding abovegroundbelowground linkages can assist restoration ecology. Trends in Ecology \& Evolution 25, 670-679.

Kirk, J.L., Beaudette, L.A., Hart, M., Moutoglis, P., Klironomos, J.N., Lee, H., Trevors, J.T., 2004. Methods of studying soil microbial diversity. Journal of Microbiological Methods 58, 169-188.

Kohler, J., Caravaca, F., Azcón, R., Díaz, G., Roldán, A., 2016. Suitability of the microbial community composition and function in a semiarid mine soil for assessing phytomanagement practices based on mycorrhizal inoculation and amendment addition. Journal of Environmental Management 169, 236-246.

Kõljalg, U., Nilsson, R.H., Abarenkov, K., Tedersoo, L., Taylor, A.F., Bahram, M., Bates, S.T., Bruns, T.D., Bengtsson-Palme, J., Callaghan, T.M., Douglas, B., Drenkhan, T., Eberhardt, U., Dueñas, M., Grebenc, T., Griffith, G.W., Hartmann, M., Kirk, P.M., Kohout, P., Larsson, E., Lindahl, B.D., Lücking, R., Martín, M.P., Matheny, P.B., Nguyen, N.H., Niskanen, T., Oja, J., Peay, K.G., 
Peintner, U., Peterson, M., Põldmaa, K., Saag, L., Saar, I., Schüßler, A., Scott, J.A., Senés, C., Smith, M.E., Suija, A., Taylor, D.L., Telleria, M.T., Weiss, M., Larsson, K.H., 2013. Towards a unified paradigm for sequence-based identification of fungi. Molecular Ecology 22, 5271-5277.

Li, X., Huang, L., 2015. Toward a new paradigm for tailings phytostabilization - nature of the substrates, amendment options, and anthropogenic pedogenesis. Critical Reviews in Environmental Science and Technology 45, 813-839.

Liu, J., Sui, Y., Yu, Z., Shi, Y., Chu, H., Jin, J., Liu, X., Wang, G., 2015. Soil carbon content drives the biogeographical distribution of fungal communities in the black soil zone of northeast China. Soil Biology \& Biochemistry 83, 29-39.

Lundell, T.K., Mäkelä, M.R., Hildén, K., 2010. Lignin-modifying enzymes in filamentous basidiomycetes-ecological, functional and phylogenetic review. Journal of Basic Microbiology 50, 5-20.

Marschner, P., 2007. Soil microbial community structure and function assessed by FAME, PLFA and DGGE - advantages and limitations. In: Varma, A., Oelmüller, R., eds. Advanced Techniques in Soil Microbiology. Vol 11. Berlin: Springer, 181-200

Mendez, M.O., Maier, R.M., 2008. Phytostabilization of mine tailings in arid and semiarid environments-an emerging remediation technology. Environmental Health Perspectives 116, 278-283.

Mulligan, D.R., Gillespie, M.J., Gravina, A.J., Currey, N.A., 2006. An assessment of the direct revegetation strategy on the tailings storage facility at Kidston gold mine, North Queensland, Australia. In: Fourie, A., Tibbett, M., eds. Proceedings of the First International Seminar on Mine Closure. Perth: Australian Centre for Geomechanics, 371-381

Nemergut, D.R., Townsend, A.R., Sattin, S.R., Freeman, K.R., Fierer, N., Neff, J.C., Bowman, W.D., Schadt, C.W., Weintraub, M.N., Schmidt, S.K., 2008. The effects of chronic nitrogen fertilization on alpine tundra soil microbial communities: implications for carbon and nitrogen cycling. Environmental Microbiology 10, 3093-3105.

Oksanen, J., Blanchet, F.G., Kindt, R., Legendre, P., Minchin, P.R., O'Hara, R.B., Simpson, G.L., Solymos, P., Stevens, M.H.H., Wagner, H., 2015. Vegan: Community Ecology Package, R package version 2.3-1

Pennanen, T., Frostegard, A., Fritze, H., Baath, E., 1996. Phospholipid fatty acid composition and heavy metal tolerance of soil microbial communities along two heavy metal-polluted gradients in coniferous forests. Applied and Environmental Microbiology 62, $420-428$.

Pitt, J.I., Samson, R.A., Frisvad, J.C., 2000. List of accepted species and their synonyms in the family Trichocomaceae. In: Samson RA, Pitt JI, eds. Integration of modern taxonomic methods for Penicillium and Aspergillus classification. Amsterdam: Harwood Academic Publishers, 9-79

Rastogi, G., Sani, R.K., 2011. Molecular techniques to assess microbial community structure, function, and dynamics in the environment. In: Ahmad, I., Ahmad, F., Pichtel, J., eds. Microbes and microbial technology: agricultural and environmental applications. New York: Springer, 29-57

Renella, G., Landi, L., Ascher, J., Ceccherini, M.T., Pietramellara, G., Mench, M., Nannipieri, P., 2008. Long-term effects of aided phytostabilisation of trace elements on microbial biomass and activity, enzyme activities, and composition of microbial community in the Jales contaminated mine spoils. Environmental Pollution 152, 702-712.

Roseby, S.J., Mulligan, D.R., Menzies, N.W., Ritchie, P.J., Currey, N. A., 1998. Ecosystem development on tailings at Kidston Gold Mine, North Queensland, Australia. In: Fox HR, Moore HM, Mclntosh $A D$, eds. Land reclamation: achieving sustainable benefits. Rotterdam: A. A. Balkema, 137-142

Rousk, J., Bååth, E., Brookes, P.C., Lauber, C.L., Lozupone, C., Caporaso, J.G., Knight, R., Fierer, N., 2010. Soil bacterial and fungal communities across a $\mathrm{pH}$ gradient in an arable soil. ISME Journal 4, 1340-1351.

Schloss, P.D., Westcott, S.L., Ryabin, T., Hall, J.R., Hartmann, M., Hollister, E.B., Lesniewski, R.A., Oakley, B.B., Parks, D.H., Robinson, C.J., Sahl, J.W., Stres, B., Thallinger, G.G., Van Horn, D.J., Weber, C.F., 2009. Introducing mothur: open-source, platform-independent, community-supported software for describing and comparing microbial communities. Applied and Environmental Microbiology 75, 7537-7541.

Shokralla, S., Spall, J.L., Gibson, J.F., Hajibabaei, M., 2012. Nextgeneration sequencing technologies for environmental DNA research. Molecular Ecology 21, 1794-1805.

Shukla, M.K., Lal, R., Ebinger, M.H., 2005. Physical and chemical properties of a minespoil eight years after reclamation in northeastern Ohio. Soil Science Society of America Journal 69, 1288 1297.

Solís-Domínguez, F.A., Valentín-Vargas, A., Chorover, J., Maier, R.M., 2011. Effect of arbuscular mycorrhizal fungi on plant biomass and the rhizosphere microbial community structure of mesquite grown in acidic lead/zinc mine tailings. Science of the Total Environment 409, 1009-1016.

Sun, S., Badgley, B.D., 2019. Changes in microbial functional genes within the soil metagenome during forest ecosystem restoration. Soil Biology \& Biochemistry 135, 163-172.

Tedersoo, L., Kõljalg, U., Hallenberg, N., Larsson, K.H., 2003. Fine scale distribution of ectomycorrhizal fungi and roots across substrate layers including coarse woody debris in a mixed forest. New Phytologist 159, 153-165.

Thavamani, P., Samkumar, R.A., Satheesh, V., Subashchandrabose, S.R., Ramadass, K., Naidu, R., Venkateswarlu, K., Megharaj, M., 2017. Microbes from mined sites: Harnessing their potential for reclamation of derelict mine sites. Environmental Pollution 230, 495-505.

Tilman, D., Wedin, D., Knops, J., 1996. Productivity and sustainability influenced by biodiversity in grassland ecosystems. Nature 379 , 718-720.

Tordoff, G.M., Baker, A.J.M., Willis, A.J., 2000. Current approaches to the revegetation and reclamation of metalliferous mine wastes. Chemosphere 41, 219-228.

Valentín-Vargas, A., Root, R.A., Neilson, J.W., Chorover, J., Maier, R. M., 2014. Environmental factors influencing the structural dynamics of soil microbial communities during assisted phytostabilization of acid-generating mine tailings: a mesocosm experiment. Science of the Total Environment 500-501, 314-324.

van der Heijden, M.G., Bardgett, R.D., van Straalen, N.M., 2008. The unseen majority: soil microbes as drivers of plant diversity and 
productivity in terrestrial ecosystems. Ecology Letters 11, 296310.

Volant, A., Héry, M., Desoeuvre, A., Casiot, C., Morin, G., Bertin, P.N., Bruneel, O., 2016. Spatial distribution of eukaryotic communities using high-throughput sequencing along a pollution gradient in the arsenic-rich creek sediments of Carnoulès mine, France. Microbial Ecology 72, 608-620.

Wang, Q., Garrity, G.M., Tiedje, J.M., Cole, J.R., 2007. Naive Bayesian classifier for rapid assignment of rRNA sequences into the new bacterial taxonomy. Applied and Environmental Microbiology 73, 5261-5267.

Whitelaw, M.A., 1999. Growth promotion of plants inoculated with phosphate-solubilizing fungi. Advances in Agronomy 69, 99-151.

Whiteway, M., Tebung, W.A., Choudhury, B.I., Rodríguez-Ortiz, R., 2015. Metabolic regulation in model ascomycetes-adjusting similar genomes to different lifestyles. Trends in Genetics 31, 445-453.

Xu, L., Ravnskov, S., Larsen, J., Nilsson, R.H., Nicolaisen, M., 2012. Soil fungal community structure along a soil health gradient in pea fields examined using deep amplicon sequencing. Soil Biology \& Biochemistry 46, 26-32.
Yang, S.X., Liao, B., Yang, Z.H., Chai, L.Y., Li, J.T., 2016. Revegetation of extremely acid mine soils based on aided phytostabilization: A case study from southern China. Science of the Total Environment 562, 427-434.

Yang, T.T., Liu, J., Chen, W.C., Chen, X., Shu, H.Y., Jia, P., Liao, B., Shu, W.S., Li, J.T., 2017. Changes in microbial community composition following phytostabilization of an extremely acidic Cu mine tailings. Soil Biology \& Biochemistry 114, 52-58.

Yao, Q., Liu, J., Yu, Z., Li, Y., Jin, J., Liu, X., Wang, G., 2017. Three years of biochar amendment alters soil physiochemical properties and fungal community composition in a black soil of northeast China. Soil Biology \& Biochemistry 110, 56-67.

Yilmaz, N., Visagie, C.M., Houbraken, J., Frisvad, J.C., Samson, R.A., 2014. Polyphasic taxonomy of the genus Talaromyces. Studies in Mycology 78, 175-341.

Yu, L.H., Jia, W.L., Xue, Y.Z., 2009. Survey and analysis of the copper tailing resources in China. Metal Mine 8, 179-181.

Zornoza, R., Acosta, J.A., Martínez-Martínez, S., Faz, A., Bååth, E., 2015. Main factors controlling microbial community structure and function after reclamation of a tailing pond with aided phytostabilization. Geoderma 245, 1-10. 